\title{
Novel Targeted Agents for the Treatment of Bladder Cancer: Translating Laboratory Advances into Clinical Application
}

\author{
Xiaoping Yang, Thomas W. Flaig \\ Department of Medicine, Division of Medical Oncology, University of Colorado Denver School of \\ Medicine
}

\begin{abstract}
Bladder cancer is a common and frequently lethal cancer. Natural history studies indicate two distinct clinical and molecular entities corresponding to invasive and non-muscle invasive disease. The high frequency of recurrence of noninvasive bladder cancer and poor survival rate of invasive bladder cancer emphasizes the need for novel therapeutic approaches. These mechanisms of tumor development and promotion in bladder cancer are strongly associated with several growth factor pathways including the fibroblast, epidermal, and the vascular endothelial growth factor pathways. In this review, efforts to translate the growing body of basic science research of novel treatments into clinical applications will be explored.
\end{abstract}

Key words: bladder neoplasms; drug therapy; vascular endothelial growth factors; epidermal growth factors; fibroblast growth factors

Int Braz. J Urol. 2010; 36: 273-82

\section{INTRODUCTION}

Bladder cancer is common with 68,810 new cases and 14,100 deaths estimated in the United States in 2008. It is the fourth most common cancer in men and the ninth most common cancer in women (1). For patients with metastatic disease, the systemic chemotherapy regimen of methotrexate, vinblastine, doxorubicin, and cisplatin (MVAC) has been the foundation of systemic therapy for many years. More recently, the chemotherapy combination of gemcitabine and cisplatin (GC) has gained greater acceptance and largely replaced MVAC for the treatment of advanced bladder cancer, based on a phase III study comparing the two regimens in patients with locally advanced or metastatic bladder cancer (2). While not clearly powered as a non-inferiority trial, the 5 year overall survival was $13.0 \%$ versus $15.3 \%$ for GC and MVAC, respectively. With similar efficacy and significantly reduced toxicity, GC has been adopted as a standard, first-line regimen for advanced bladder cancer.

In the second or third-line setting, several traditional chemotherapy agents offer modest activity. Prior to the widespread use of GC, weekly gemcitabine was examined in patients with bladder cancer who had previously been treated with a platinum-based regimen with an overall response rate of $22.5 \%$ (3). These promising results lead to the development of the GC combination in the first line setting (4). Pemetrexed, a multi-targeted anti-folate agent, was more recently tested in previously treated patients with advanced bladder cancer. The objective response rate was $28 \%$ with a small number of patients experiencing a complete response; however, the median time to progression was short (less than 3 months) (5). Anti-microtubule agents are also active in bladder cancer and have been evaluated in the first and second-line setting. Paclitaxel demonstrated clear 
activity in a small study of bladder cancer patients who had failed or were unfit for standard first-line therapy (6). A current first-line regimen used in patients unable to receive cisplatin-based chemotherapy combines paclitaxel, carboplatin and gemcitabine. This tripledrug combination revealed an objective response rate of $68 \%$, with approximately half of these as complete responses (7). Additionally, a phase II trial evaluated a different taxane, docetaxel, in patients who had progressed despite cisplatin-based chemotherapy with an objective response rate of $13 \%$, but a short duration of response, ranging from 3 to 8 months (8). The activity of docetaxel in bladder cancer was also later tested in chemotherapy-naïve patients with a higher response rate of $31 \%(9)$.

Over the last 10 years, significant advances have been made in the integration of new biologicallytargeted agents in the treatment of cancer. Approximately $20 \%$ of breast cancer patients have over-expression or amplification of HER2/neu (EGFR2). Herceptin, a monoclonal antibody which targets HER2/neu, is now commonly used in breast cancer patients with HER2/ neu expression yielding significant improvement in both the progression free (10) and overall survival (11). The use of single agent cetuximab (Erbitux), a monoclonal antibody against the epidermal growth factor receptor (EGFR), demonstrates significant activity in patients with advanced colorectal cancer (12). Subsequent analysis showed that patients with an activating K-ras mutation, downstream of EGFR, receive no benefit from cetuximab. This allows for the selection of an enriched K-ras wild-type treatment population, excluding those with little chance of benefit (13). Bevacizumab (Avastin) is a monoclonal antibody that binds to the vascular endothelial growth factor (VEGF), which is over-expressed in many cancer types including lung cancer. The addition of bevacizumab to standard chemotherapy significantly improves the overall survival of patients with lung cancer, although the rates of significant bleeding are increased (14). In renal cell carcinoma (RCC) traditional cytotoxic chemotherapy has little objective activity. A new class of agents, the small-molecule, multi-kinase inhibitors, have recently been approved for the treatment of advanced RCC. Both sunitinib and sorafenib target an array of pro-growth kinases including the vascular endothelial growth factor receptor (VEGFR) kinases.
As documented in phase III randomized trials, sunitinib and sorafenib produce significant disease stabilization and a small number of objective responses in patients with RCC $(15,16)$.

There are many examples of the successful use of targeted agents in modern cancer therapeutics. Despite the prevalence of bladder cancer, the availability of several potential targets in bladder cancer and the successful inhibition of these targets in many other cancer types, no biologic agents are currently in clinical use for the treatment of bladder cancer. We will review the current state of pre-clinical evaluation of targeted agents for bladder cancer and the potential impact of these agents in the clinical management of bladder cancer.

\section{MOLECULAR PATHWAYS IN BLADDER CANCER}

Two distinct developmental pathways for bladder tumors have been characterized (17). The first is that of a noninvasive papillary lesion without penetration of the epithelial basement membrane (Ta tumor). Aberrant expression of fibroblast growth factor receptor 3 (FGFR3), RAS and PIK3CA appear to play a critical role in the development of low grade and generally non-invasive bladder tumors (18). Approximately $20 \%$ of tumors are muscle invasive at diagnosis and the prognosis in these cases is poor, with less than $50 \%$ survival at 5 years (17). Tumors that penetrate the basement membrane (T1) or invade the bladder muscle (T2) are therefore much more clinically concerning and are associated with different biologic aberrancy, including common p53 mutations. These distinct pathways of tumor development with such different clinical outcomes imply that specific strategies for the management of these tumors should be developed.

\section{FIBROBLAST GROWTH FACTOR RECEPTOR (FGFR)}

Both basic science and preclinical investigations indicate that FGFR mutation and over-expression are seen commonly and occur early in the development of non-invasive bladder cancer (19). 
Activating point mutations of the FGFR have been identified in approximately $40 \%$ of bladder tumors. In the FGFR family, FGFR3 is most prominent in normal urothelial cells, with only low levels of FGFR 1, 2 and 4 observed by real-time reverse transcriptase PCR (20). Further, mutations of FGFR3 are common in urothelial papillomas, which are considered to be a precursor for papillary bladder cancer, suggesting that FGFR3 mutation occurs early in the process of tumor development (21). In addition to the mutational status of FGFR3, protein overexpression of FGFR3 has been found commonly in bladder tumors, but not in normal bladder tissue (22).

Although the clinical usefulness of FGFR inhibition is not yet known, several pre-clinical evaluations have examined this approach in bladder cancer. The stable expression of a small hairpin RNA (shRNA) against FGFR3 in bladder cancer cells demonstrates an inhibition of cancer cell growth, supporting the central importance of this pathway in bladder cancer (23). Additionally, human single chain Fv antibody fragments that recognize the extracellular domain of FGFR3 have been isolated and characterized (24). This antibody inhibits ligand-binding by the wild-type receptor and has been shown to inhibit the growth of xenografts expressing FGFR3 in S249C bladder cancer cells (24). The high frequency of FGFR mutation in superficial bladder tumors suggests the possibility of utilizing an intravesical approach targeting FGFR in such patients. In vivo studies demonstrate activity using a toxic fusion protein targeting FGFR3 in human bladder cancer cells over-expressing this receptor (25).

\section{EPIDERMAL GROWTH FACTOR RECEPTOR (EGFR)}

Compared to the FGFR pathway, targeting the epidermal growth factor receptor (EGFR) pathway is in a more mature phase, with the successful use of this approach in the clinical setting of several other cancer types. In addition, significant pre-clinical evaluation of this pathway has been undertaken. EGFR was first characterized in invasive and superficial bladder cancer in 1989 (26). Abnormal expression of the urothelial EGFR and/or altered excretion of EGF may well precede overt manifestations of transitional cell carcinoma
(TCC) and thus may serve as an early marker of the invasive phenotype; the degree of EGFR overexpression in bladder tumors has been shown to correlate with tumor stage and grade (27). Laboratory investigations have shown that stimulation of the EFGR pathway both increases proliferation and the migration of bladder cancer cells (28). Work to identify the predictive markers for the response of bladder cancer cells to EGFR inhibition is underway, using a broad spectrum of bladder cancer cell lines (29). Surprisingly, there is no correlation between expression of EGF, the ligand of EGFR and the activity of EGFR inhibitors in bladder cancer cells (29). Activating mutations of EGFR, a key predictive marker for the activity of EGFR inhibitors in non-small cell lung cancer (30), are uncommon in TCC of the bladder (31).

Given the importance of EGFR in the biology of bladder cancer, a number of therapeutic strategies against EGFR to treat bladder cancer are being evaluated. Blockade of EGFR by monoclonal antibodies has been assessed in several malignancies including bladder cancer. Among several anti-EGFR monoclonal antibodies under clinical development, cetuximab (IMC-C225) inhibits EGFR downstream signaling, cell cycle arrest, angiogenesis and metastasis and is the most widely studied (32). The effect of this monoclonal antibody on bladder cancer cells in an animal model has been reported (29). Another anti-EGFR monoclonal antibody, panitumumab (ABX-EGF), has been shown to have a potent effect on several tumors such as metastatic colorectal carcinoma, although its application in bladder cancer is not known (33).

EGFR tyrosine kinase inhibitors, such as gefitinib (ZD 1839) and erlotinib (OSI-774), have been extensively studied in bladder cancer models. Preclinical data demonstrate that gefitinib selectively inhibits proliferation and angiogenesis in human bladder cancer cells (34). Erlotinib inhibits the activation of epidermal growth factor receptor, mitogen activated protein kinase, Akt and STAT3 $(35,36)$.

\section{HUMAN EPIDERMAL GROWTH FACTOR RECEPTOR 2 (HER2/NEU)}

HER2/neu overexpression and to a lesser extent, amplification, are observed in bladder cancer, 
suggesting the potential utility of HER $2 /$ neu-targeted therapy in patients with advanced TCC (37). In a Japanese study of patients with bladder tumors, immunohistochemical staining demonstrated HER2/neu expression in $42.5 \%$ (38). More notably, according to the classification of grade, $60 \%$ of pT 4 patients were HER2/neu positive (38). Recently, a multicenter phase II study has reported that $52.3 \%$ of metastatic urothelial carcinomas are Her2/neu positive using the DAKO HercepTest Diagnostic and fluorescence in situ hybridization (FISH) (39), consistent with the result of the Japanese group (38). The anti-tumor effect of TAK-165, a new potent inhibitor of the HER2/neu tyrosine kinase, has been studied in bladder cancer. Using a xenograft mouse model with the human bladder cancer cell (UMUC3) TAK-165 treatment resulted in $22.9 \%$ growth inhibition compared with the control group at 14 days (40).

It should be noted that the role of HER2/neu in the development of bladder cancer has not been clearly defined. Although HER2/neu is up-regulated in invasive bladder cancers, its overall expression in bladder cancer cells is less than in breast cancer cells (40). Recently, a small study reports that there is a poor association between HER2/neu protein overexpression and gene amplification, in contrast to findings in breast cancer (41). Additionally, Dinney et al. reported that the expression of HER4, but not HER2/neu or HER3, correlates with stage, grade, and survival (42). These reports raise the possibility that our understanding of the biology of HER2/neu based on breast cancer evaluations may not be directly translated into therapeutic strategies for bladder cancer.

\section{VASCULAR ENDOTHELIAL GROWTH FACTOR (VEGF)}

VEGF and its receptor are critically important in the process of angiogenesis and therefore play a vital role in the tumor growth and metastasis. The VEGF pathway was first characterized in bladder cancer in 1993 (43). While VEGF expression is observed in many patients with low or intermediate grade T1 bladder cancer, higher levels of VEGF RNA expression may be a predictor of a more aggressive form of bladder cancer with earlier cancer recurrence (44). Recent work has shown that the protein expression of VEGF in bladder cancer tissue correlates with increased tumor stage (45) and the serum levels of VEGF are directly associated with bladder cancer stage (46). VEGF binds to several cognate tyrosine kinase receptors: VEGFR1, VEGFR2 and VEGFR3. Of these, VEGFR2 appears to be the most attractive target since its expression correlates with the pathologic stage in urothelial carcinoma cell lines and bladder tumors (47).

Based on these preclinical observations, several animal studies and clinical trials have been designed for this target. Neutralizing monoclonal antibody targeted at murine VEGFR2 (DC101, ImClone Systems) has been combined with paclitaxel, with its efficacy tested in an orthotopic bladder cancer xenograft model (48). This combination demonstrated significant anti-neoplastic activity. It is likely that the observed activity is via inhibition of angiogenesis in addition to the induction of both tumor cell and endothelial cell apoptosis. The anti-tumor activity of single-agent DC101 has been examined in an orthotopic nude mouse tumor model with human 253J-BV bladder tumors (49). DC101 therapy resulted in a decrease in VEGFR-2 phosphorylation and an increase in endothelial cell and tumor cell apoptosis (49), but did not completely inhibit tumor angiogenesis when used as a single-agent (49). A VEGF-A splice variant protein conjugated with gelonin has also been utilized to target the VEGF pathway (50). Gelonin is a plant toxin with high cytotoxicity at very low doses (nM range). The VEGF-A splice variant protein serves as a targeting component to specifically guide and internalize the conjugate into the cancer cells with high VEGF expression. This fusion protein suppresses tumor growth in an orthotopic bladder cancer xenograft model (50), and has been validated in prostate and breast cancer with the goal of preventing cancer metastasis $(51,52)$.

\section{ANGIOGENESIS AND ITS INHIBITORS}

Angiogenesis is a rate-limiting step in tumor growth and the inhibition of new blood vessel development may play a critical role in controlling tumor invasion and metastasis. The management of 
bladder cancer with anti-angiogenesis strategies is still in the early phase of implementation. In addition to the VEGF pathway, other targets in the vascular compartment may be considered including the endothelin (ET)-axis and the angiopoietin-Tie pathway. The endothelin family (ET-1, ET-2, and ET-3) is a group of potent vasoconstricting peptides (53). ET-1 has been studied most extensively and has been shown to modulate endothelial cell proliferation, migration, invasion, and microtubule formation. More interestingly, ET-1 increases VEGF mRNA expression and VEGF protein levels, indicating probable cross-talk between the endothelin-axis and VEGF signaling (54). Compared with normal urothelium, increased expression of ET-1 and the associated endothelinA- and endothelin-B-receptors has been found in the vast majority of invasive bladder cancer specimens (55). Overexpression of the endothelin-B-receptor appears to be associated with a better clinical prognosis than with the over-expression of the endothelin-Areceptor (56). Furthermore, overexpression of ET-1 is associated with up-regulation of the micro-vessel density which may impact the clinical aggressiveness of the tumor. These data suggest that the ET -axis may represent a novel therapeutic target in bladder cancer that is largely unexplored. Interestingly, the phase II clinical testing of single-agent bosentan, a dual ET-receptor antagonist, to treat stage IV melanoma patients has been reported, with stable disease noted in some patients (57). The use of atrasentan, an inhibitor of the endothelin-A-receptor, did not meet its primary endpoint of delayed time to progression in a large phase III study, but did slow the rate of prostate specific antigen rise in blood (58), additional phase III testing with atrasentan in prostate cancer is underway.

Tie2, another angiogenic pathway, has received less attention since it was only recently fully described and characterized. Tie 2 is the tyrosine kinase receptor of angiopoietin-1(Ang-1) and angiopoietin-2 (Ang-2) $(59,60)$. This pathway has an active angiogenic phase in which blood vessel differentiation by migration/sprouting is promoted; there is also a separate anti-apoptotic effect that is seen with Tie2 signaling. Interestingly, although upregulation of Ang-1 and Ang-2 has consistently been demonstrated in many cancer types, their direct role in tumor development is controversial (61). Recently, serum levels of Ang-1, Ang-2 and Tie-2 have been examined in bladder cancer (62). High serum levels of Tie 2 are correlated with shorter metastasis-free survival in both univariate and in multivariate analysis, suggesting that Tie2 expression may be an independent risk factor for metastasis.

\section{CLINICAL USE OF TARGETED AGENTS IN UROTHELIAL CANCER}

Accrual to bladder cancer trials has been poor in recent years, especially in the front-line setting (63). Accordingly, there have been a limited number of clinical trials using biologic targeted receptor kinases in bladder cancer, with many of these clinical studies only reported in abstract form. The clinical pursuit of specific agents for use in bladder cancer is based largely on the experience gained from their use for other tumor types such as lung and breast cancer.

Trastuzumab is commonly used in the treatment of breast cancer and has received significant attention as a therapeutic agent for bladder cancer in light of the HER2/neu expression seen in malignant bladder tissue. As a single agent, trastuzumab does not have clear activity against urothelial cancer. In 7 patients with transitional cell carcinoma of the bladder and HER2/neu protein over-expression, weekly trastuzumab did not yield any objective responses, although 1 patient did achieve stable disease (64). Another study examined trastuzumab in 6 patients with metastatic transitional cell carcinoma and HER2/neu overexpression by immunohistochemistry (IHC) (65). Trastuzumab was given with standard carboplatin and paclitaxel chemotherapy in 4 of the patients, with paclitaxel in 1 patient and as a single-agent in 1 patient; 2 of the participants were chemotherapy naïve. Partial responses were seen in all 6 treated patients with initial tumor regressions of $30-80 \%$.

The largest published study to date on the use of trastuzumab in bladder cancer was led by the Southwest Oncology Group (39). Of 109 screened advanced urothelial cancer patients, 52\% had HER $2 /$ neu overexpression by any method, with the majority of these as protein over-expression (49\% IHC, $14 \%$ FISH, $12 \%$ serum assessment). Forty-four of 
these chemotherapy-naïve patients were treated with trastuzumab, carboplatin, paclitaxel and gemcitabine. The primary endpoint of this study was the assessment of cardiac toxicity from this regimen, which was seen in 23\% (grade 1-3). Secondarily, the objective response rate was $57 \%$ with five complete responses. The median time to progression was 9.3 months and the median survival was 14.1 months.

While it is difficult to make firm conclusions from these non-randomized and small studies, significant trastuzumab activity in bladder cancer has not been demonstrated to date. As we discussed earlier, while HER2/neu protein over-expression is commonly seen in bladder cancer, gene amplification is much less common $(39,66)$, although some investigators find a better correlation with IHC status of HER2/neu and gene amplification (67). While protein over-expression of HER2/neu is a predictive marker for trastuzumab responses in breast cancer, this may not necessarily be true for bladder cancer. As with many biologic agents, the identification of predictive markers (e.g. K-ras status with cetuximab) (13) are critical to the successful testing and use of targeted agents.

Lapatinib is an orally available inhibitor of EGFR and HER2/neu, and is currently in clinical use for the treatment of breast cancer. Fifty-nine patients with locally advanced or metastatic transitional cell carcinoma with progression despite a platinum-containing front-line regimen were treated with lapatinib (68). Independent radiological review revealed 1 partial response and 18 patients with stable disease. The median time to progression was short ( 8.6 weeks). Additional biomarker predictors of response are being investigated.

Inhibition of the VEGFR pathway has been preliminarily examined in bladder cancer patients. A single-case report describes a man with metastatic transitional cell carcinoma and squamous differentiation treated with bevacizumab. At 24 months, the patient was reported to have minimal toxicity and a sustained response, suggesting anecdotal activity (69). Sorafenib is a multi-kinase inhibitor with prominent VEGFR inhibition. Treatment with sorafenib has been evaluated in one study of 14 patients with untreated advanced urothelial cancer (70). There were no objective responses, although 4 patients experienced stable disease; the median time to progression was 1.8 months. A second larger study examined the use of sorafenib in 27 patients with urothelial cancer with progression after front-line therapy (71). There were no objective responses noted with a median progression-free survival of 2.2 months. A related small molecule inhibitor, sunitinib, was examined as a first-line treatment in bladder cancer in those deemed unable to receive standard cisplatin-based chemotherapy. Two of 16 treated patients had a partial response and 8 participants had at least 6 months of stable disease (72). A second study of sunitinib examined patients with carcinoma of the urothelium who had progressed after 1-4 previous chemotherapy (73). In this significantly pre-treated population, 3 of 45 patients had a partial response and 11 had stable disease. While preliminary, these results suggest modest activity of sunitinib as a single-agent in bladder cancer.

In other cancer types studied, targeted therapeutic agents are generally most effective when combined with cytotoxic chemotherapy. While this is a rationale approach to explore in bladder cancer, there are very limited published data describing the combination treatments in this setting. Gefitinib, an oral EGFR inhibitor, has been evaluated with cisplatin and gemcitabine in 55 patients with advanced urothelial cancer (74). An objective response was observed in $51 \%$ with a median overall survival of 14 months. While these efficacy data are similar to standard gemcitabine and cisplatin, it is not clear that gefitinib is the most suitable biologic agent to integrate with cytotoxic chemotherapy, given the large negative studies using this approach in lung cancer $(75,76)$.

\section{PERSPECTIVES}

The current treatment of advanced bladder cancer relies heavily on traditional cytotoxic agents, despite the tumor expression of many targets of emerging biologic agents currently available. Preclinical evaluation reveals several new agents with encouraging in vivo data, targeting FGFR, the VEGF-pathway, ET-axis, HER2/neu and EGFR. The translation of these laboratory findings into the clinical treatment of patients with urothelial cancer has 
been slow, with little published information currently available. It is important to note that the accessibility of the bladder offers unique opportunities to deliver novel therapies directly to the site of the tumor, but dramatically improved accrual to bladder cancer trials will be needed to rapidly test and select the next generation of treatment for those with bladder cancer.

\section{CONFLICT OF INTEREST}

None declared.

\section{REFERENCES}

1. Jemal A, Siegel R, Ward E, Hao Y, Xu J, Murray T, et al.: Cancer statistics, 2008. CA Cancer J Clin. 2008; 58: 71-96.

2. von der Maase H, Sengelov L, Roberts JT, Ricci S, Dogliotti L, Oliver T, et al.: Long-term survival results of a randomized trial comparing gemcitabine plus cisplatin, with methotrexate, vinblastine, doxorubicin, plus cisplatin in patients with bladder cancer. J Clin Oncol. 2005; 23: 4602-8.

3. Lorusso V, Pollera CF, Antimi M, Luporini G, Gridelli C, Frassineti GL, et al.: A phase II study of gemcitabine in patients with transitional cell carcinoma of the urinary tract previously treated with platinum. Italian Co-operative Group on Bladder Cancer. Eur J Cancer. 1998; 34: 1208-12.

4. Kaufman D, Raghavan D, Carducci M, Levine EG, Murphy B, Aisner J, et al.: Phase II trial of gemcitabine plus cisplatin in patients with metastatic urothelial cancer. J Clin Oncol. 2000; 18: 1921-7.

5. Sweeney CJ, Roth BJ, Kabbinavar FF, Vaughn DJ, Arning M, Curiel RE, et al.: Phase II study of pemetrexed for second-line treatment of transitional cell cancer of the urothelium. J Clin Oncol. 2006; 24: 3451-7.

6. Dreicer R, Gustin DM, See WA, Williams RD: Paclitaxel in advanced urothelial carcinoma: its role in patients with renal insufficiency and as salvage therapy. J Urol. 1996; 156: 1606-8.

7. Hussain M, Vaishampayan U, Du W, Redman B, Smith DC: Combination paclitaxel, carboplatin, and gemcitabine is an active treatment for advanced urothelial cancer. J Clin Oncol. 2001; 19: 2527-33.

8. McCaffrey JA, Hilton S, Mazumdar M, Sadan S, Kelly WK, Scher HI, et al.: Phase II trial of docetaxel in patients with advanced or metastatic transitional-cell carcinoma. J Clin Oncol. 1997; 15: 1853-7.

9. de Wit R, Kruit WH, Stoter G, de Boer M, Kerger J, Verweij J: Docetaxel (Taxotere): an active agent in metastatic urothelial cancer; results of a phase II study in non-chemotherapy-pretreated patients. $\mathrm{Br} \mathrm{J}$ Cancer. 1998; 78: 1342-5.

10. Piccart-Gebhart MJ, Procter M, Leyland-Jones B, Goldhirsch A, Untch M, Smith I, et al.: Trastuzumab after adjuvant chemotherapy in HER2-positive breast cancer. N Engl J Med. 2005; 353: 1659-72.

11. Romond EH, Perez EA, Bryant J, Suman VJ, Geyer CE Jr, Davidson NE, et al.: Trastuzumab plus adjuvant chemotherapy for operable HER2-positive breast cancer. N Engl J Med. 2005; 353: 1673-84.

12. Jonker DJ, O'Callaghan CJ, Karapetis CS, Zalcberg JR, Tu D, Au HJ, et al.: Cetuximab for the treatment of colorectal cancer. N Engl J Med. 2007; 357: 2040-8.

13. Karapetis CS, Khambata-Ford S, Jonker DJ, O'Callaghan CJ, Tu D, Tebbutt NC, et al.: K-ras mutations and benefit from cetuximab in advanced colorectal cancer. N Engl J Med. 2008; 359: 1757-65.

14. Sandler A, Gray R, Perry MC, Brahmer J, Schiller JH, Dowlati A, et al.: Paclitaxel-carboplatin alone or with bevacizumab for non-small-cell lung cancer. N Engl J Med. 2006; 355: 2542-50. Erratum in: N Engl J Med. 2007; 356: 318 .

15. Motzer RJ, Hutson TE, Tomczak P, Michaelson MD, Bukowski RM, Rixe O, et al.: Sunitinib versus interferon alfa in metastatic renal-cell carcinoma. $\mathrm{N}$ Engl J Med. 2007; 356: 115-24.

16. Escudier B, Eisen T, Stadler WM, Szczylik C, Oudard $\mathrm{S}$, Siebels M, et al.: Sorafenib in advanced clear-cell renal-cell carcinoma. N Engl J Med. 2007; 356: 12534. Erratum in: N Engl J Med. 2007; 357: 203.

17. Mitra AP, Cote RJ: Molecular pathogenesis and diagnostics of bladder cancer. Annu Rev Pathol. 2009; 4: 251-85.

18. Mitra AP, Datar RH, Cote RJ: Molecular pathways in invasive bladder cancer: new insights into mechanisms, progression, and target identification. J Clin Oncol. 2006; 24: 5552-64.

19. Knowles MA: Novel therapeutic targets in bladder cancer: mutation and expression of FGF receptors. Future Oncol. 2008; 4: 71-83.

20. Tomlinson DC, Baldo O, Harnden P, Knowles MA: FGFR3 protein expression and its relationship to mutation status and prognostic variables in bladder cancer. J Pathol. 2007; 213: 91-8.

21. Hernández S, López-Knowles E, Lloreta J, Kogevinas M, Amorós A, Tardón A, et al.: Prospective study of 
FGFR3 mutations as a prognostic factor in nonmuscle invasive urothelial bladder carcinomas. J Clin Oncol. 2006; 24: 3664-71.

22. Mhawech-Fauceglia P, Cheney RT, Fischer G, Beck A, Herrmann FR: FGFR3 and p53 protein expressions in patients with pTa and pT1 urothelial bladder cancer. Eur J Surg Oncol. 2006; 32: 231-7.

23. Tomlinson DC, Hurst CD, Knowles MA: Knockdown by shRNA identifies S249C mutant FGFR3 as a potential therapeutic target in bladder cancer. Oncogene. 2007; 26: 5889-99.

24. Martínez-Torrecuadrada J, Cifuentes G, López-Serra P, Saenz P, Martínez A, Casal JI: Targeting the extracellular domain of fibroblast growth factor receptor 3 with human single-chain Fv antibodies inhibits bladder carcinoma cell line proliferation. Clin Cancer Res. 2005; 11: 6280-90.

25. Martínez-Torrecuadrada JL, Cheung LH, López-Serra P, Barderas R, Cañamero M, Ferreiro S, et al.: Antitumor activity of fibroblast growth factor receptor 3 -specific immunotoxins in a xenograft mouse model of bladder carcinoma is mediated by apoptosis. Mol Cancer Ther. 2008; 7: 862-73.

26. Smith K, Fennelly JA, Neal DE, Hall RR, Harris AL: Characterization and quantitation of the epidermal growth factor receptor in invasive and superficial bladder tumors. Cancer Res. 1989; 49: 5810-5.

27. Chow NH, Liu HS, Lee EI, Chang CJ, Chan SH, Cheng HL, et al.: Significance of urinary epidermal growth factor and its receptor expression in human bladder cancer. Anticancer Res. 1997; 17: 1293-6.

28. Messing EM: Growth factors and bladder cancer: clinical implications of the interactions between growth factors and their urothelial receptors. Semin Surg Oncol. 1992; 8: 285-92.

29. Black PC, Brown GA, Inamoto T, Shrader M, Arora A, Siefker-Radtke AO, et al.: Sensitivity to epidermal growth factor receptor inhibitor requires E-cadherin expression in urothelial carcinoma cells. Clin Cancer Res. 2008; 14: 1478-86.

30. Lynch TJ, Bell DW, Sordella R, Gurubhagavatula S, Okimoto RA, Brannigan BW, et al.: Activating mutations in the epidermal growth factor receptor underlying responsiveness of non-small-cell lung cancer to gefitinib. N Engl J Med. 2004; 350: 2129-39.

31. Blehm KN, Spiess PE, Bondaruk JE, Dujka ME, Villares GJ, Zhao YJ, et al.: Mutations within the kinase domain and truncations of the epidermal growth factor receptor are rare events in bladder cancer: implications for therapy. Clin Cancer Res. 2006; 12: 4671-7.
32. Kim ES, Khuri FR, Herbst RS: Epidermal growth factor receptor biology (IMC-C225). Curr Opin Oncol. 2001; 13: 506-13.

33. Wu M, Rivkin A, Pham T: Panitumumab: human monoclonal antibody against epidermal growth factor receptors for the treatment of metastatic colorectal cancer. Clin Ther. 2008; 30: 14-30.

34. KassoufW, Brown GA, Black PC, Fisher MB, Inamoto T, Luongo T, et al.: Is vascular endothelial growth factor modulation a predictor of the therapeutic efficacy of gefitinib for bladder cancer? J Urol. 2008; 180: 1146-53.

35. Jacobs MA, Wotkowicz C, Baumgart ED, Neto BS, Rieger-Christ KM, Bernier T, et al.: Epidermal growth factor receptor status and the response of bladder carcinoma cells to erlotinib. J Urol. 2007; 178: 1510-4.

36. Yang JL, Qu XJ, Hayes VM, Brenner PC, Russell PJ, Goldstein D: Erlotinib (OSI-774)-induced inhibition of transitional cell carcinoma of bladder cell line growth is enhanced by interferon-alpha. BJU Int. 2007; 99: 1539-45.

37. Hansel DE, Swain E, Dreicer R, Tubbs RR: HER2 overexpression and amplification in urothelial carcinoma of the bladder is associated with MYC coamplification in a subset of cases. Am J Clin Pathol. 2008; 130: 274-81.

38. Yamada Y, Naruse K, Nakamura K, Aoki S, Taki T, Tobiume $\mathrm{M}$, et al.: Potential for molecular-targeted therapy targeting human epidermal growth factor receptor-2 for invasive bladder cancer. Oncol Rep. 2007; 18: 3-7.

39. Hussain MH, MacVicar GR, Petrylak DP, Dunn RL, Vaishampayan U, Lara PN Jr, et al.: Trastuzumab, paclitaxel, carboplatin, and gemcitabine in advanced human epidermal growth factor receptor-2/neu-positive urothelial carcinoma: results of a multicenter phase II National Cancer Institute trial. J Clin Oncol. 2007; 25: 2218-24. Erratum in: J Clin Oncol. 2008; 26: 3295.

40. Nagasawa J, Mizokami A, Koshida K, Yoshida S, Naito K, Namiki M: Novel HER2 selective tyrosine kinase inhibitor, TAK-165, inhibits bladder, kidney and androgen-independent prostate cancer in vitro and in vivo. Int J Urol. 2006; 13: 587-92.

41. Caner V, Turk NS, Duzcan F, Tufan NL, Kelten EC, Zencir S, et al.: No strong association between HER$2 /$ neu protein overexpression and gene amplification in high-grade invasive urothelial carcinomas. Pathol Oncol Res. 2008; 14: 261-6.

42. Black PC, Dinney CP: Growth factors and receptors as prognostic markers in urothelial carcinoma. Curr Urol Rep. 2008; 9: 55-61. 
43. Brown LF, Berse B, Jackman RW, Tognazzi K, Manseau EJ, Dvorak HF, et al.: Increased expression of vascular permeability factor (vascular endothelial growth factor) and its receptors in kidney and bladder carcinomas. Am J Pathol. 1993; 143: 1255-62.

44. Crew JP, O'Brien T, Bradburn M, Fuggle S, Bicknell $\mathrm{R}$, Cranston D, et al.: Vascular endothelial growth factor is a predictor of relapse and stage progression in superficial bladder cancer. Cancer Res. 1997; 57: 5281-5.

45. Yang CC, Chu KC, Yeh WM: The expression of vascular endothelial growth factor in transitional cell carcinoma of urinary bladder is correlated with cancer progression. Urol Oncol. 2004; 22: 1-6.

46. Bernardini S, Fauconnet S, Chabannes E, Henry PC, Adessi G, Bittard H: Serum levels of vascular endothelial growth factor as a prognostic factor in bladder cancer. J Urol. 2001; 166: 1275-9.

47. Xia G, Kumar SR, Hawes D, Cai J, Hassanieh L, Groshen S, et al.: Expression and significance of vascular endothelial growth factor receptor 2 in bladder cancer. J Urol. 2006; 175: 1245-52.

48. Inoue K, Slaton JW, Davis DW, Hicklin DJ, McConkey DJ, Karashima T, et al.: Treatment of human metastatic transitional cell carcinoma of the bladder in a murine model with the anti-vascular endothelial growth factor receptor monoclonal antibody DC101 and paclitaxel. Clin Cancer Res. 2000; 6: 2635-43.

49. Davis DW, Inoue K, Dinney CP, Hicklin DJ, Abbruzzese JL, McConkey DJ: Regional effects of an antivascular endothelial growth factor receptor monoclonal antibody on receptor phosphorylation and apoptosis in human 253J B-V bladder cancer xenografts. Cancer Res. 2004; 64: 4601-10.

50. Mohamedali KA, Kedar D, Sweeney P, Kamat A, Davis DW, Eve BY, et al.: The vascular-targeting fusion toxin VEGF 121/rGel inhibits the growth of orthotopic human bladder carcinoma tumors. Neoplasia. 2005; 7 : 912-20.

51. Mohamedali KA, Poblenz AT, Sikes CR, Navone NM, Thorpe PE, Darnay BG, et al.: Inhibition of prostate tumor growth and bone remodeling by the vascular targeting agent VEGF121/rGel. Cancer Res. 2006; 66: 10919-28.

52. Ran S, Mohamedali KA, Luster TA, Thorpe PE, Rosenblum MG: The vascular-ablative agent $\operatorname{VEGF(121)/~}$ rGel inhibits pulmonary metastases of MDA-MB-231 breast tumors. Neoplasia. 2005; 7: 486-96.

53. Bagnato A, Spinella F, Rosanò L: The endothelin axis in cancer: the promise and the challenges of molecu- larly targeted therapy. Can J Physiol Pharmacol. 2008; 86: 473-84.

54. Bagnato A, Rosanò L, Spinella F, Di Castro V, Tecce R, Natali PG: Endothelin B receptor blockade inhibits dynamics of cell interactions and communications in melanoma cell progression. Cancer Res. 2004; 64: 1436-43.

55. Wülfing C, Eltze E, Piechota H, Abol-Enein H, Wülfing P, Bode ME, et al.: Expression of endothelin-1 and endothelin- $A$ and $-\mathrm{B}$ receptors in invasive bladder cancer. Oncol Rep. 2005; 13: 223-8.

56. Wülfing C, Eltze E, Yamini J, Wülfing P, Bierer S, Böcker $\mathrm{W}$, et al.: Expression of the endothelin axis in bladder cancer: relationship to clinicopathologic parameters and long-term survival. Eur Urol. 2005; 47: 593-600.

57. Kefford R, Beith JM, Van Hazel GA, Millward M, Trotter JM, Wyld DK, et al.: A phase II study of bosentan, a dual endothelin receptor antagonist, as monotherapy in patients with stage IV metastatic melanoma. Invest New Drugs. 2007; 25: 247-52.

58. Nelson JB, Love W, Chin JL, Saad F, Schulman CC, Sleep DJ, et al.: Phase 3, randomized, controlled trial of atrasentan in patients with nonmetastatic, hormonerefractory prostate cancer. Cancer. 2008; 113: 247887.

59. Davis S, Aldrich TH, Jones PF, Acheson A, Compton $\mathrm{DL}$, Jain V, et al.: Isolation of angiopoietin-1, a ligand for the TIE2 receptor, by secretion-trap expression cloning. Cell. 1996; 87: 1161-9.

60. Maisonpierre PC, Suri C, Jones PF, Bartunkova S, Wiegand SJ, Radziejewski C, et al.: Angiopoietin-2, a natural antagonist for Tie2 that disrupts in vivo angiogenesis. Science. 1997; 277: 55-60.

61. Shim WS, Ho IA, Wong PE: Angiopoietin: a TIE(d) balance in tumor angiogenesis. Mol Cancer Res. 2007; 5: 655-65.

62. Szarvas T, Jäger T, Droste F, Becker M, Kovalszky I, Romics I, et al.: Serum levels of angiogenic factors and their prognostic relevance in bladder cancer. Pathol Oncol Res. 2009; 15: 193-201.

63. Dreicer R, Manola J, Roth BJ, See WA, Kuross S, Edelman MJ, et al.: Phase III trial of methotrexate, vinblastine, doxorubicin, and cisplatin versus carboplatin and paclitaxel in patients with advanced carcinoma of the urothelium. Cancer. 2004; 100: 1639-45.

64. Salzberg M, Borner M, Bauer JA, Morant R, Rauch D, Rochlitz C: Trastuzumab (Herceptin) in patients with HER-2-overexpressing metastatic or locally advanced transitional cell carcinoma of the bladder: report on 7 patients. Eur J Cancer. 2006; 42: 2660-1. 
65. Peyromaure M, Scotté F, Amsellem-Ouazana D, Vieillefond A, Oudard S, Beuzeboc P: Trastuzumab (Herceptin) in metastatic transitional cell carcinoma of the urinary tract: report on six patients. Eur Urol. 2005; 48: 771-5; discussion 775-8.

66. Latif Z, Watters AD, Dunn I, Grigor K, Underwood MA, Bartlett JM: HER2/neu gene amplification and protein overexpression in G3 pT2 transitional cell carcinoma of the bladder: a role for anti-HER2 therapy? Eur J Cancer. 2004; 40: 56-63.

67. de Pinieux G, Colin D, Vincent-Salomon A, Couturier J, Amsellem-Ouazana D, Beuzeboc P, et al.: Confrontation of immunohistochemistry and fluorescent in situ hybridization for the assessment of HER-2/ neu (cerbb-2) status in urothelial carcinoma. Virchows Arch. 2004; 444: 415-9.

68. Wülfing C, Machiels J, Richel D, Grimm M, Treiber U, de Groot M, et al.: A single arm, multicenter, open label, ph II study of lapatinib as 2L treatment of pts with locally advanced/metastatic transitional cell carcinoma (TCC) of the urothelial tract. J Clin Oncol. 2005; 23: 16S (Abstract \#4594).

69. Osai WE, Ng CS, Pagliaro LC: Positive response to bevacizumab in a patient with metastatic, chemotherapy-refractory urothelial carcinoma. Anticancer Drugs. 2008; 19: 427-9.

70. Sridhar SS, Winquist E, Eisen A, Hotte SJ, Elaine M, Mukherjee SD, et al.: A phase II study of first-line sorafenib (Bay 43-9006) in advanced or metastatic urothelial cancer. A trial of the $\mathrm{PMH}$ Phase II Consortium. 2008 Genitourinary Cancers Symposium: (Abstract \#340).
71. Dreicer R, Li H, Stein MN, DiPaola RP, Eleff M, Roth BJ, et al.: Phase II trial of sorafenib in advanced carcinoma of the urothelium (E 1804): A trial of the Eastern Cooperative Oncology Group. J Clin Oncol. 2008; 26: 15S (Abstract \#5083).

72. Bellmunt J, Maroto P, Mellado B, Carles J, Calvo E, Alcaraz A, et al.: Phase II study of sunitinib as first line treatment in patients with advanced urothelial cancer ineligible for cisplatin-based chemotherapy. 2008 Genitourinary Cancers Symposium: (Abstract \#291).

73. Gallagher DJ, Milowsky MI, Gerst SR, Iasonos A, Boyle MG, Trout A.: Final results of a phase II study of sunitinib in patients (pts) with relapsed or refractory urothelial carcinoma (UC). J Clin Oncol. 2008; 26: (Abstract \#5082).

74. Philips G, Sanford B, Halabi S, Bajorin D, Small EJ: Phase II study of cisplatin (C), gemcitabine $(\mathrm{G})$ and gefitinib for advanced urothelial carcinoma (UC): Analysis of the second cohort of CALGB 90102. J Clin Oncol. 2006; 24: $18 \mathrm{~S}$ (Abstract \#4578).

75. Giaccone G, Herbst RS, Manegold C, Scagliotti G, Rosell R, Miller V, et al.: Gefitinib in combination with gemcitabine and cisplatin in advanced non-small-cell lung cancer: a phase III trial--INTACT 1. J Clin Oncol. 2004; 22: 777-84.

76. Herbst RS, Giaccone G, Schiller JH, Natale RB, Miller V, Manegold C, et al.: Gefitinib in combination with paclitaxel and carboplatin in advanced non-small-cell lung cancer: a phase III trial--INTACT 2. J Clin Oncol. 2004; 22: 785-94.

\section{Correspondence address:}

Dr. Thomas W. Flaig

Division of Medical Oncology

University of Colorado Denver School of Medicine

12801 E. $17^{\text {th }}$ Avenue, Room L18-8117

Aurora, CO, 80045, USA

Fax: + 1303 724-3889

E-mail: thomas.flaig@uchsc.edu 